\title{
ENTRE O DISCURSO OFICIAL E O DISCURSO KINIKINAU: AS REPRESENTAÇÕES DE ESCOLA E TERRITÓRIO ${ }^{1}$
}

\author{
Daniele Lucena SANTOS ${ }^{2}$ \\ Claudete Cameschi de SOUZA ${ }^{3}$
}

\begin{abstract}
Resumo: Baseando-nos no discurso do documento oficial das Diretrizes Curriculares Nacionais para a Educação Escolar Indígena na Educação Básica (2012) e no discurso do povo Kinikinau, temos como objetivo problematizar a construção identitária dos Kinikinau e analisar as representações de escola e território que perpassam esses discursos. A fim de buscar, valendo-nos das regularidades enunciativas, as formações discursivas e os interdiscursos que tecem os fios discursivos, visando uma discussão sobre os efeitos de sentido gerados, desenvolvemos este artigo sob a perspectiva transdisciplinar da Análise do Discurso de linha Francesa, dialogando com os Estudos Culturalistas, e pautando-nos no processo de referenciação linguística e no método arqueogenealógico foucaultiano (2008, 2012). Partindo dos estudos de Authier-Revuz (1998); Coracini (2007); Foucault (2008, 2012); Orlandi (2008, 2009); Pêcheux (1988); Bauman (2005); Castells (2010) e Hall (2012), constatamos que os Kinikinau, estando em território de fronteira, ressignificam suas práticas sociais, e que o discurso do documento oficial aponta para representações de escola e território atravessadas por formações discursivas e interdiscursos atrelados a questões políticas, contrariando os objetivos pelos quais foi criado e divergindo das representações construídas pelos Kinikinau, articuladas em princípios culturais.
\end{abstract}

Palavras-chave: Kinikinau. Escola. Território. Identidade.

\footnotetext{
${ }^{1}$ Artigo elaborado com base em uma pesquisa de Mestrado concluída em fevereiro de 2017.

${ }^{2}$ UFMS - Universidade Federal de Mato Grosso do Sul - Departamento de Letras. Três Lagoas - Mato Grosso do Sul - Brasil. 79640-210 - lucena.ufms@hotmail.com

${ }^{3}$ UFMS - Universidade Federal de Mato Grosso do Sul - Departamento de Letras. Três Lagoas - Mato Grosso do Sul - Brasil. 79640-210 - claudetecameschi@gmail.com
} 


\section{Entre a extinção e o renascer: o povo Kinikinau}

Nativos da região do Gran Chaco, popularmente chamado de Chaco Paraguaio, os índios Kinikinau, remanescentes da nação Chané-Guaná compartilham de um histórico de sofrimento, bem como todos os índios em nosso país. Após a travessia para o Brasil, em aproximadamente 1850 (SOUZA, 2008, p. 38), motivada por disputas de terras, esse povo buscou construir uma nova história, entretanto, as perseguições não cessaram e o sonho de um território próprio tornou-se cada vez mais distante.

Com a eclosão da Guerra da Tríplice Aliança, a popular Guerra do Paraguai, agravaram-se os conflitos por território, gerando novamente a dispersão dos Kinikinau. Na tentativa de sobreviver às constantes perseguições por terra, esse povo assumiu a identidade Terena. Unindo-se aos Terena, grupo com maior visibilidade e número de membros, os Kinikinau silenciaram sua identidade étnica em face da sobrevivência, mas, por volta de 1970, foram vítimas de um etnocídio ao serem considerados extintos por renomados pesquisadores, e invisibilizados pelos órgãos competentes: primeiro pelo Serviço de Proteção ao Índio (SPI) e depois pela Fundação Nacional do Índio (Funai), já que “as crianças que nasciam na aldeia eram registradas como Terena” (SOUZA, 2012, p. 19).

Desde 1940, orientados pelo extinto Serviço de Proteção ao Índio (SPI), os Kinikinau residem na Aldeia São João, Reserva Indígena Kadiwéu, próxima do município de Bonito/MS, juntamente com os Terena e os Kadiwéu, donos da terra. Há informações, no entanto, de que "quatro famílias migraram dessa aldeia em virtude dos atritos com os Kadiwéu e atualmente moram na Terra Indígena de Cachoeirinha, no Assentamento Mãe Terra, em Miranda, junto com os Terena” (SANTOS; SOUZA, 2014, p. 7).

Três décadas de (in)visibilidade se passaram, no entanto, o sentimento de pertença e o desejo de lutar por seu povo nunca enfraqueceram, assim, determinados, continuam a (re)escrever sua história, buscando o reconhecimento da sociedade hegemônica e de seus direitos garantidos na Constituição Federativa de 1988.

Autodeclarar-se Kinikinau foi uma decisão gerada pela proposta de instalação de uma escola na Aldeia São João, que, atendendo à demanda da comunidade, onde a maioria é Kinikinau, recebeu o nome de Escola Municipal Indígena Koinukunoen ${ }^{4}$. A construção

\footnotetext{
${ }^{4}$ Na língua indígena, Koinukunoen significa Kinikinau.
} 
dessa escola permitiu o fortalecimento do povo no espaço em que vivem e o trilhar de um novo caminho, mas, ainda que a tensão tenha aumentado pela construção da instituição, os Kinikinau, sobretudo, se valem deste ambiente para reivindicar seu lugar de cidadãos brasileiros, em especial, seu lugar de índio brasileiro, muitas vezes silenciado pelo Estado.

Refletindo acerca da relação tecida pelos Kinikinau, compreendemos que, relacionados de maneira inerente, a escola e o território são dois conceitos que atravessam o processo identitário desse povo. Nesse viés, partimos do pressuposto de que ambos ultrapassam as concepções limítrofes de espaço educacional e extensão geográfica, assumindo, pelas práticas do grupo, uma nova representação. Levantamos, diante desse contexto, a hipótese de que a escola representa para os Kinikinau um microterritório em terras Kadiwéu, garantindo o fortalecimento identitário e a revitalização de sua cultura e língua, além de se constituir como um espaço no qual a democracia é efetivada.

\section{Entrelaçando conceitos}

Pautando-nos na perspectiva transdisciplinar da Análise do Discurso de vertente francesa (AD), com base no processo de referenciação linguística e no método arqueogenealógico foucaultiano (2008, 2012), este artigo tem como objetivo problematizar o processo identitário do indígena e analisar discursivamente como são construídas as representações de escola e território que se presentificam nos discursos das Diretrizes Curriculares Nacionais para a Educação Escolar Indígena na Educação Básica (2012) e dos Kinikinau.

Para alcançar tais objetivos, investigamos os sentidos que emergem desses discursos, via materialidade da língua e da história, permitindo-nos refletir sobre as raízes das significações. A exterioridade exerce um papel importante porque nos remete ao espaço, refere-se às condições de produções, liga a aparição à regularidade dos enunciados, tornando-se fundamental para o rastreamento dos acontecimentos que difundiram uma determinada série discursiva, ou seja, chegar ao campo de enunciado em que estes se produziram.

No seio de sua produção "um enunciado tem sempre margens povoadas de outros enunciados” (FOUCAULT, 2008, p. 110), o que nos permite compreender que todo enunciado reverbera outros discursos, e pode ser condicionado a uma propriedade 
interdiscursiva. Cabe esclarecer, no entanto, que a concepção de discurso vai além de um lugar da real resistência que permite os sentidos emergirem. Na visão foucaultiana (2008, p. 133-134), o discurso é “constituído de um número limitado de enunciados para os quais podemos definir um conjunto de condições de existência”. Assim, pensar o discurso é também considerar que a sua produção se dá em uma conjuntura sócio-histórica e ideológica específica, e que sua aparição é sempre recorrente de conflito, instigada por poder e resistência e emergente na descontinuidade.

Em razão disso, Foucault (2008, p. 55) explica que o discurso é descontínuo porque nasce do devir, de rupturas efetivadas por censura que levam o sujeito, em um movimento de dispersão, a uma multiplicidade de posições e funções. Para o historiador (FOUCAULT, 2008), o sujeito, como uma fabricação do social, pode ocupar várias posições e identificar-se com cada uma delas, o que mudará serão as regras, a ordem das discursividades. Como explica Fischer (2013, p. 131), “o sujeito do discurso não é uma pessoa, alguém que diz alguma coisa; trata-se antes de uma posição que alguém assume, diante de um certo discurso".

Nessa perspectiva, os discursos são produzidos em face das posições ocupadas pelos sujeitos, além de elementos que afetam suas discursividades, uma vez que "os sujeitos funcionam pelo inconsciente e pela ideologia”, primeiro porque o sujeito não tem controle absoluto de seu dizer, e os sentidos não são completos em razão da opacidade e equivocidade da língua; segundo porque o seu dizer não é neutro, está sempre ligado a diferentes perspectivas ideológicas (ORLANDI, 2009, p. 20). A autora acresce à sua colocação que "é na língua que a ideologia se materializa”.

A ideologia é apreendida como um complexo jogo de relações que incitam o sujeito à existência e que determinam, historicamente, “o que é e o que deve ser” das palavras e dos sentidos a elas conferidos (PÊCHEUX, 1988, p. 159). Ao serem envolvidos por uma determinada ideologia, os sentidos ficam condicionados a ela, logo o sujeito não tem o controle total do que diz e dos sentidos que emanam de seu discurso, referendando os esquecimentos $\mathrm{n}^{0} 1$ e $\mathrm{n}^{0} 2$ de Pêcheux (1988). Isso ocorre em decorrência das experiências e dos discursos que ecoam no (in)consciente, de já-ditos, que formam um mecanismo de "filtragem", de seleção e apagamentos enunciativos acerca de um determinado objeto como, por exemplo, o índio. Essa espécie de filtro é que vai formar uma memória discursiva. 
O processo de produção dos sentidos, portanto, vinculado a uma ideologia, obedecendo a regularidades no funcionamento do discurso e determinando "o que pode e deve ser dito” (ORLANDI, 2009, p. 43), é o que chamamos de formação discursiva. Compreendemos, assim, que as formações discursivas estão subordinadas às formações ideológicas. Foucault (2008, p. 43) afirma que quando se “[...] puder descrever, entre um certo número de enunciados, semelhante sistema de dispersão [...] se puder definir uma regularidade [...] diremos, por convenção, que se trata de uma formação discursiva”.

Nessa esteira, a noção de que a produção dos discursos está sempre relacionada à interdiscursividade nos permite afirmar que, em um discurso, coabitam inúmeros outros, pois quando um discurso está ligado a outro por vozes que se manifestam e que interferem na nossa interpretação, estamos diante da interdiscursividade.

Visto que a relação interdiscursiva ecoa em nosso (in)consciente, podemos inferir que é por meio dela que se constrói a memória discursiva. Essa é uma concepção muito rica, já que o objeto de nosso estudo é o discurso indígena e que, concomitantemente, recorremos ao passado em face de responder inquietações do presente. Mas, antes de adentrarmos a noção de memória, um outro conceito também de fundamental importância é o de arquivo, discorrido por Foucault (2008). Entrelaçado aos conceitos de discurso, interdiscurso e formação discursiva, já discutidos, o arquivo constitui-se como um princípio de enunciabilidade, isto é, o arquivo é que permite que os enunciados encampem sentidos. Para Foucault (2008, p. 143-144), arquivo é como “a lei do que pode ser dito, o sistema que rege o aparecimento dos enunciados como acontecimentos singulares. [...] São todos esses sistemas de enunciados (acontecimentos de um lado, coisas de outro) que proponho chamar de arquivo".

A partir de tal junção, devemos pensar a memória discursiva como sendo um pano de fundo na produção discursiva, "aquilo que, face a um texto que surge como acontecimento a ler, vem estabelecer os 'implícitos’ de que sua leitura necessita” (ACHARD, 1999, p. 52). Para além do domínio da restituição, do resgate do fio de significância, a memória transcende essa perspectiva ao gerar esquecimentos, que “transformam e silenciam sentidos”, afirma Baronas (2011, p. 103).

Desse modo, nossa tarefa enquanto analistas do discurso "consiste em problematizar os enunciados concretos em sua historicidade, descrevendo e analisando 
os fatores que permitiram que esses enunciados se inter-relacionassem, se negassem, se excluíssem, se substituíssem” (SOUSA, 2011, p. 112).

Assim, é relevante dizer que buscamos, perpassando todos esses conceitos, encontrar, pelas camadas sedimentares da história, as relações de poder que viabilizam determinadas discursividades e escamoteiam outras. No entanto, como a linguagem na perspectiva discursiva não é transparente e passível de falhas, utilizamos o método arqueogenealógico de Foucault $(2008,2012)$, que nos permitiu problematizar os processos de subjetivação dos sujeitos e "escavar" os enunciados em busca de regularidades que façam emergir a ordem das escolhas discursivas desse sujeito.

Com relação à questão identitária, é pertinente discutirmos esses processos em decorrência das desestabilizações dos processos históricos que embasaram as “identidades fixas” e que entraram em colapso, no estado de incertezas incitadas, na maioria das vezes, por lutas e contestações políticas, fazendo surgir novas identidades.

O sociólogo Bauman (2005, p. 17-18) corrobora que tanto o pertencimento quanto a identidade não são sólidos, pelo contrário “são negociáveis e revogáveis”. O sujeito e todas as coisas no mundo são fluidos e móveis, e, assim, como a identidade, não há nada determinado, tudo está em movimento. O autor atribui à noção de identidade a complexidade de um quebra-cabeça, com peças conflitantes e que nunca se completam. Ele acrescenta que "uma identidade coesa, firmemente fixada e solidamente construída seria um fardo, uma repressão, uma limitação da liberdade de escolha” (BAUMAN, 2005, p. 60).

Sublinhamos que a construção da identidade de um sujeito é perpassada por inúmeros conflitos, desencontros, desgastes provocados pelos choques da diferença. Emerge, assim, um sujeito formado como um mosaico, em que cada componente consubstanciado de diversos outros promove a criação de um ser multifacetado, interpretável de diversas maneiras.

Com o foco em analisar os discursos das Diretrizes e dos Kinikinau, visando rastrear as construções representativas de escola e território/terra, já que os tomamos como sinônimos, e os processos de identificação do povo, selecionamos seis recortes, sendo três retirados do documento oficial, denominados de R1, R2 e R3, e dois, R5 e R6, de uma entrevista realizada em setembro de 2015 com um membro da comunidade, o qual chamamos de SP1 (Sujeito Professor 1). Cabe frisar que, consoante aos nossos 
objetivos de compreender as representações de escola e território, buscamos estabelecer um paralelo entre ambos os discursos, a fim de observar em quais pontos dialogam e em quais se divergem.

\section{Um olhar discursivo: representações de escola e território}

Assim como outros dispositivos disciplinares, a lei é apresentada à sociedade como uma forma de proteção, caracterizando, por conseguinte, o Estado como cuidador de seus cidadãos. Como é possível observarmos, a lei, na prática, funciona, todavia, como uma ferramenta de normatização da sociedade, que busca “corrigir” o que não se enquadra em seu padrão, ajustando o que foge à ordem de sua hegemonia. O discurso legislador carrega, como premissa, um discurso moderno, por um lado, mas que, por outro, desvela uma compreensão limitada do mundo hodierno, em especial do mundo indígena.

Nesse sentido, o documento das Diretrizes (2012) é um importante condicionante na construção da identidade dos sujeitos, pois à medida que sua função é organizar a conduta destes na sociedade, em face de uma ideologia dominante, o sujeito curva-se à governamentalidade para não fugir à ordem hegemônica. Essas diretrizes, portanto, configurando-se como um dispositivo, uma rede de poderes, estão vinculadas a outro(s) discursos(s) que "estão sempre em movimento, sempre em mudança, sempre em formação” (CORACINI, 2007, p. 119), a fim de abranger todos os povos. As dúvidas surgem no limiar da interpretação: a lei inclui ou exclui?

É fundamental ressaltarmos que esse documento, enquanto arquivo, entrelaça-se com resultantes estratégias e conhecimentos, fazendo com que uma rede de formações discursivas se conserve em uma sociedade. Diante disso, o discurso da lei promove a (des)(re)construção das identidades e o agenciamento de discursos modalizadores sobre inclusão e exclusão, tendo em vista que “todo arquivo responde a estratégias institucionais de organização e conservação de documentos e acervos, criando, por meio delas, a gestão da memória de uma sociedade” (ZOPPI-FONTANA, 2005, p. 97).

Após a leitura do documento legal, identificamos relações interdiscursivas que visam regulamentar os povos, desprezando, de certo modo, suas especificidades em face de uma única ideologia. Essas diretrizes são, atualmente, referências para o ensino nas 
comunidades, uma vez que regem a aplicabilidade dos princípios da escolarização na sociedade indígena e delegam aos povos maneiras de (con)viver no espaço escolar, entretanto, a(s) voz(es) que ecoa(m) no/do documento não são indígenas.

O sistema de ensino a que se refere o documento é a escola. Caracterizada como uma das mais antigas instituições, a escola passou por diversas transformações desde sua inserção nas comunidades indígenas no século XVI. Nesse sentido, a proposta de educação escolar indígena versada pelo documento desliza os sentidos e nos permite construir a representação de escola na qual se respalda.

A fim de fundamentar nossas colocações, expomos R1 expressando que essas diretrizes devem (grifo nosso):

R1: Art. $2^{\circ}$ VIII - zelar para que o direito à educação escolar diferenciada seja garantido às comunidades indígenas com qualidade social e pertinência pedagógica, cultural, linguística, ambiental e territorial, respeitando as lógicas, saberes e perspectivas dos próprios povos indígenas.

Em R5, é frisada a função regulamentadora do documento por meio do verbo zelar, do qual surge o sentido de “cuidar”, “administrar” (BECHARA, 2011, p. 1150), conferindo uma representação de inábil ao indígena, remetendo à formação discursiva jurídica. A articulação de verbos dessa natureza como, por exemplo, orientar, assegurar, fortalecer, também presentes no documento, estabelece relação com fios interdiscursivos de outros documentos, a saber, o Estatuto do Índio, que denomina os índios de "silvícolas" e “incapazes”. Presentifica-se, com o uso desse verbo, a interpretação de que os índios não dispõem de habilidades para gerir sua própria escola e modos próprios de ensinoaprendizagem, cabendo ao Estado a "responsabilidade” de zelar para que os direitos dessas comunidades sejam "garantidos".

Recorrente no discurso, destacamos novamente a palavra diferenciada, adjetivando a educação escolar a ser disponibilizada nas comunidades. No eixo dos sentidos, o documento busca a "união", contudo, ao lançarmos o olhar para os sentidos que estão à margem, veremos que a comunhão nacional nunca será atingida enquanto o discurso cristalizado de "igualdade" estiver atravessado pelo discurso colonizador de exclusão das diferenças. Ocorre que os indígenas são subjugados por meio de vários 
mecanismos de dominação, como a lei, por exemplo, que não lhes permite ter identidade(s) e que sejam iguais na diferença.

Constatamos, assim, a ação hegemônica e incisiva da lei sobre essas comunidades, uma vez que, mesmo discorrendo sobre a instalação de escolas que promovam uma ação intercultural e uma educação destinada às comunidades, abrangendo suas especificidades, expressam uma ação "diferenciada”, de que emerge o sentido de desigualdade, contradizendo os seus objetivos de incluir os índios. A voz do branco presentifica-se numa relação interdiscursiva com o Estatuto do Índio (1973), a Constituição Federal (1988), a Lei de Diretrizes e Bases da Educação (LDB, No 9.394, 1996), o Referencial Curricular para as Escolas Indígenas (1998), o Plano Nacional de Educação e o Parecer 14 (1999), em que a voz do branco emerge para legislar sobre populações caracterizadas por práticas e culturas singulares, e que, enquadrando-as em uma lei, busca homogeneizar a sociedade.

Tal ação colabora para a estereotipação e a marginalização não somente dos indígenas, mas também dos negros, por exemplo, que foram civilizados segundo os padrões e conceitos do brancocentrismo, estabelecendo uma fronteira entre esses sujeitos, os selvagens, incapazes e os brancos, civilizados e responsáveis pelas ações que versam ambas as comunidades.

Vale dizer que a condição de tutela do indígena, ainda que tenha sido revogada, parece reger o discurso jurídico no que se refere à questão indígena, pois, no decorrer do discurso das diretrizes, o frequente uso de verbos como “zelar”, “orientar”, “reconhecer”, “coordenar”, entre outros, faz com que prevaleça o tom de necessidade: um discurso de modalidade deôntica que escamoteia o autoritarismo. Com isso, estabelece uma conjuntura para a ação escolar nas comunidades, consorciando ao Estado o poder de legislar, ou seja, de estabelecer regras e domínios em áreas cuja jurisprudência, apesar de alcançável, não é capaz de perpassar o simbólico dos povos.

O que buscamos expor, com tais afirmações, é que a lei, apesar de ter como função proteger, zelar e garantir o direito e a justiça, não alcança esses objetivos, já que, historicamente, as leis reverberam a "mais pura das vontades de verdade, cuja produção e interpretação são extremamente regradas” (GÓIS, 2013, p. 167), e atendem a uma ideologia dominante, (re)produzindo, dessa forma, discursos de exclusão e silenciamento. 
Outro termo de relevância a ser discutido é o garantido, pois ao produzir o efeito de sentido de inclusão e onipotência do legislador, já que este será o agente responsável por asseverar o usufruto do direito indígena a uma educação escolar indígena, emerge e solidifica-se a imagem de um Estado comprometido em proteger e assegurar a todos, em especial aos indígenas, os seus direitos.

A preposição “com” condiciona critérios a serem seguidos para o desenvolvimento da proposta educacional, caracterizados pelas expressões qualidade social e pertinência pedagógica, cultural, linguística, ambiental e territorial, e embasados na perspectiva do branco. Nossa afirmação decorre de que, a partir do imaginário social do branco, tais critérios não existem nessas comunidades, bem como a educação necessária para torná-los sujeitos de seus direitos.

Nesse contexto, a escola posta à disposição desses povos, com base em uma educação diferenciada, revestida de um papel inclusivo, é ofertada às comunidades com uma “maquiagem”, isto é, há apenas uma transposição do sistema educacional do branco. Apreendemos, portanto, que o modelo de escola indígena proposto no documento e considerado adequado é o desenvolvido pelo branco, contribuindo para discursividades colonialistas e que continuam a escrever sobre o indígena de 500 anos atrás. Apesar da busca da “inclusão”, agenciada por conceitos que assegurem uma diferença na igualdade, conforme propõe o documento desde o início, reforça-se o discurso excludente no momento em que restringe, ou direciona, com base em discursos hegemônicos, o sistema escolar.

A representação de escola que atravessa o documento é a de uma instituição que molda as práticas das comunidades, tendo como objetivo colonizá-las para, aos poucos, integrar os índios à sociedade do branco, isto é, colocar o indígena "dentro de uma racionalidade ocidental, forçando-o a perder sua identidade e abraçar outra” (GÓIS, 2013, p. 160). Um exemplo visível é que as escolas instaladas nas aldeias pelos brancos visam atender desde o calendário letivo ao material didático do branco, inviabilizando a transmissão de práticas tradicionais indígenas em prol de uma exigência política.

Em seguida, o verbo no gerúndio (“respeitando”) traz à reflexão uma ação que se dá constantemente, que se arrasta desde os antepassados dos povos, e que, embora enraizada no discurso de inclusão, engendra outras possíveis interpretações. O verbo respeitar, segundo Bechara (2011, p. 1007), equivale a “considerar”, em consonância à 
busca do sentido do verbo aceitar, que significa “concordar”, "admitir” (BECHARA, 2011, p. 221). Isso faz-nos refletir sobre a multiplicidade de interpretações que emergem do termo "respeitar”. Assim questionamos: o sentido de concordar e aceitar, disseminados pelo referente “inclusão”, recorrente nas diretrizes, caminha na mesma orientação argumentativa do termo "respeitar”? A resposta é não. Salientamos que, nesse contexto, respeitar transita entre os sentidos de "considerar” a cultura do outro, do indígena, e de “não exterminar” (GUERRA, 2010, p. 63).

Ao afirmar que a proposta educacional deve respeitar as lógicas, saberes e práticas dos próprios povos indígenas, a diferença entre o índio e o branco é reforçada, em razão de que, ao existir algo com características diversas às que uma determinada sociedade compartilha, são criados os discursos do respeito para normalizar essas características. E, ao mesmo tempo, remete-nos ao sentido histórico dos extermínios que aconteciam nas comunidades em decorrência das diferenças culturais, quando o colonizador, por desconhecer tais práticas, subjugava esses sujeitos. E é essa diferença que não é aceita pela sociedade.

O discurso moderno cria um mundo limitado acerca das comunidades, contribuindo para a criação de um imaginário ultrapassado destes sujeitos como primitivos e atrasados. A respeito dessa questão, Orlandi (2008) diz que, no Estado brasileiro, o Estado branco promove o silenciamento do indígena não apenas enquanto sujeito, mas em sua própria existência, excluindo sua presença da sociedade nacional. A autora explica que o indígena só adquire existência no discurso do branco, tendo sua representação alinhavada pela colonialidade, e, desse modo, o índio como sujeito brasileiro é apagado, “e se produz pelos mecanismos mais variados, dos quais a linguagem, com a violência simbólica que ela representa, é um dos mais eficazes” (ORLANDI, 2009, p. 66).

O diálogo que se tem buscado estabelecer entre brancos e índios ainda é muito conflituoso, visto que a relação entre essas sociedades é conduzida por universos simbólicos diferentes e que (trans)formam e condicionam o movimento de entrar e sair de outras culturas. Desse modo, a aproximação cultural entre o branco e o indígena é mais que um simples ato, visando homogeneizar. Como estamos envolvidos pela inegável diversidade do mundo, segundo Santos (2007, p. 39), não podemos "reduzir toda a heterogeneidade do mundo a uma homogeneidade”. Esse gesto implicaria colocar à 
margem, mais uma vez, questões que desvelam a diferença e que, por sua vez, são responsáveis por corroborar a estereotipação de grupos sociais já marginalizados.

Dando continuidade às questões relacionais, paradoxalmente inerentes à identificação do sujeito, expomos R2 a fim de lançar o olhar para a possível representação de escola inscrita no discurso oficial (grifo nosso):

R2: Parágrafo único: A Educação Escolar Indígena deve se constituir num espaço de construção de relações interétnicas orientadas para a manutenção da pluralidade cultural, pelo reconhecimento de diferentes concepções pedagógicas e pela afirmação dos povos indígenas como sujeitos de direitos.

No trecho "espaço de construção de relações interétnicas" se consolida a representação de escola, que até então estava sendo construída com base no processo de escolarização dos povos, como um espaço que prioriza a construção de relações interétnicas pautadas na transmissão de conhecimentos e saberes. O verbo dever, no presente do indicativo (“deve”), corrobora o caráter de necessidade, de dever moral dessa proposta educacional, que, de acordo com o recorte, precisa ser orientada para garantir o êxito. Essa tarefa fica sob a responsabilidade do Estado, que tem a soberania para governar os sujeitos constituidores de uma determinada sociedade.

No momento em que são articulados os termos "manutenção da pluralidade cultural, pelo reconhecimento de diferentes concepções pedagógicas” descortina-se uma manobra discursiva do Estado por meio da lei, visto que a população não está mais disciplinada, apenas, na massa, ou seja, no todo, no geral, mas nos detalhes, e ao valer-se dessa perspectiva, são elencadas expressões que abarcam as sociedades em suas peculiaridades, como, por exemplo, o uso da expressão diferenciada, recorrente neste e em outros documentos.

Como sabemos, a escola trata-se de uma das mais antigas instituições. Desde a colonização, a doutrina educacional instituída pelos missionários no Brasil realizava, imbricada ao processo colonizador, um agenciamento das práticas discursivas desses sujeitos, uma vez que estes “se constituem no/pelo discurso” (ORLANDI, 2009).

No passado, a educação era imposta aos índios, que num árduo processo deveriam, atendendo aos objetivos das missões, abandonar suas práticas e adequar-se à sociedade hegemônica a fim de se constituírem como sujeitos. Isso caracterizava o processo 
civilizatório. Entretanto, mesmo num clima de hostilidade por parte dos índios, os missionários conseguiram catequizar alguns índios, "mas bastava que eles voltassem à convivência com os outros índios para que retornassem aos seus costumes e crenças” (BRASIL, 2007, p. 10).

Nesse sentido, vendo que suas estratégias não alcançaram o êxito esperado, mudanças coercitivas foram realizadas. A primordial se deu com a construção de uma proposta escolar que abolisse a integração, termo que maculou a imagem da sociedade brasileira, para dar espaço à inclusão. A proposta de uma educação que aproximasse os indígenas do branco, proporcionasse igualdade e o acesso ao ensino, conhecimentos e práticas universais, salvaguardando as diferenças, foi delegada à escola.

Paralelo a esse discurso, a escola passou a ser um direito institucionalizado, que pode ou não ser requisitado nas comunidades indígenas. Ou seja, para se ter acesso a todos esses recursos os índios precisavam curvar-se ao sistema, e aceitar a governamentalidade. A escola, portanto, veicula-se como um sistema de controle, ao qual o sujeito deve se adequar para fazer parte de um determinado grupo, entrar na "ordem do discurso" (FOUCAULT, 2012).

O sistema institucional, em especial a escola, na condição de fomentadora do processo educacional é, para Foucault (2012, p. 41), “uma maneira política de manter ou modificar a apropriação dos discursos, com os saberes e os poderes que eles trazem consigo”. Visto que a escola é concebida como um mecanismo de resistência veiculadora de “saber-poder” (FOUCAULT, 2012), ela também é responsável por moldar ou recortar os sujeitos de uma sociedade, atendendo a uma ideologia dominante.

Diante disso, ao dizer que é por meio desse espaço que se concretizará a afirmação dos povos indígenas como sujeitos de direitos, enuncia a ilegalidade desses indivíduos em terras brasileiras, e, novamente, corrobora a exclusão desses povos da sociedade nacional, remetendo-nos à interdiscursividade de integração veiculada desde a era missionária, no início da colonização. A presença do articulador de pendor conformativo “como” reverbera a intenção de moldar o indígena, sujeito que não segue a conduta ocidental, mas que, por meio do processo de escolarização, desenvolvido pelo branco, terá a “oportunidade” de tornar-se sujeito de direitos, direitos esses inalcançáveis para um cidadão que não seja brasileiro. É fundamental destacar que, apesar de se tornarem 
sujeitos de direitos, a esses povos, ainda é silenciada a identidade nacional, a identidade brasileira. Emerge, novamente, a representação de Estado protetor e generoso.

Em face dessas análises, buscando empreender, via opacidade da língua, a representação de escola, e consoante a nossos objetivos trazemos à reflexão recortes que nos permitem compreender como é construída a representação de território/terra no documento oficial, com o intuito de puxar os fios do discurso dos Kinikinau e construir tal paralelo crítico.

No documento oficial, o processo de educação escolar indígena aparece, na maioria das vezes, associado ao território, possibilitando a interpretação de que o território é um bem que antecede qualquer outro, tornando-se perene na constituição dos sujeitos. Esse bem pode, todavia, configurar o sentido material ou a valoração afetiva, a depender da situação sócio-histórica e ideológica em que o sujeito está inserido. As diretrizes determinam, com base nesse viés, que (grifo nosso):

R3: Art. $7^{\circ} \S 4^{\circ}$ : A Educação Escolar Indígena deve contribuir para o projeto societário e para o bem viver de cada comunidade indígena, contemplando ações voltadas à manutenção e preservação de seus territórios e dos recursos neles existentes.

É relevante destacar, apesar de termos explanado anteriormente, a repetição da construção de um discurso deôntico em deve contribuir, indicando a obrigatoriedade da educação escolar em alcançar seus objetivos por meio de um projeto societário e do bem viver das comunidades. O uso desse discurso, considerando a porosidade das palavras, desvela a circulação de discursos que indicam, ao contrário, o apagamento dos índios por parte da educação escolar oferecida pelo branco (AUTHIER-REVUZ, 1998).

Ao enunciar "projeto societário", o legislador referenda a produção de um movimento que integre as comunidades à sociedade nacional, pois o sentido dicionarizado do termo societário é "referente à sociedade; integrante dessa sociedade" (BECHARA, 2011, p. 1056). Em seguida, é atribuído como dever a proposta de um bem viver às comunidades, forma de estabelecer um princípio de compromisso à escola e ao Estado para com os índios, visto que a história nos relata os conflitos ideológicos gerados pela interpretação dos colonizadores acerca do "bem viver” dessas comunidades. Ou seja, o bem viver discursivizado pelo documento transita entre os sentidos arrolados na 
formação discursiva colonial, via discurso do branco, e a formação discursiva cultural, expressa pelo discurso do índio.

Para assentar tal reflexão, partimos do pressuposto de que é necessário questionar como se processa esse "bem viver”, em face da constituição histórica do legislativo brasileiro, já que pensar as condições de sua produção revela a presença, na grande maioria, de uma sociedade elitista, um grupo estabelecido por compartilhar determinados aspectos ideológicos. Esse fato reforça a equivocidade da lei e a "virtualidade dos fatos legislados” ao ser elaborada por sujeitos que estão no centro, distantes da realidade dessas comunidades e que, motivados por anseios políticos, governam para a verdadeira minoria, a elite” (ZOPPI-FONTANA, 2005, p. 93).

Ao afirmar a necessidade de contemplar, via processo de escolarização, ações voltadas à manutenção e preservação de seus territórios e dos recursos neles existentes, emergem fios de sentido que nos permitem interpretar, por meio do uso do referente “seus” (“em seus territórios”), a separação entre os territórios indígenas e os territórios do branco. Esse limite, estabelecido pelo branco, funciona ambiguamente. Por um lado, gera o sentido de oportunizar a posse de um território que já pertence a eles e, com isso, a preservação de suas tradições; por outro, o de que o Estado, ao determinar a demarcação de terras para essas comunidades, destina-os a uma condição de excluídos: é necessário que eles se mantenham em seus territórios.

A lei funciona, assim, como um texto articulado no "entrecruzamento de uma série de outros textos” (CORACINI, 1991, p. 148), adquirindo sentido e anulando outros a partir da posição que o sujeito enunciador ocupa (no caso do discurso jurídico, o legislador). Em face dessa perspectiva, ao usar os itens lexicais “manutenção” e "seus”, o sujeito reconhece a posse imemorial da terra: o território sempre foi dos indígenas.

O termo “preservação” dicionarizado traz o sentido de “colocar ao abrigo de estrago, dano” (BECHARA, 2011, p. 951) algum objeto, nesse caso, o território e os recursos nele existentes. É sabido que preservar não provém, naturalmente, do discurso do índio, mas passou a fazer parte depois das devastadoras intervenções europeias.

Para o índio, não era necessário preservar porque sua relação com a terra não atravessava implicações como o consumo desordenado e o desmatamento, e, assim, o preservar, com o sentido hoje recorrente, não se fazia necessário. Preservar era algo inato nessas comunidades. Com o passar dos anos, a relação do índio com o território foi, 
entretanto, transformada pela ação da globalização e da ideologia capitalista, acarretando o deslocamento semântico da palavra “preservação”.

A partir da ação do branco, começou a reverberar-se a necessidade de preservar, mas sob a ótica capitalista, a fim de não extinguir as naturais fontes econômicas, materiais, ou seja, os recursos neles existentes. Logo, as determinações legais intervieram e um discurso de conservação e, posteriormente, de preservação se presentificou no aparato jurídico. Houve, dessa forma, nas diretrizes, uma (re)atualização enunciativa, mas que ainda evoca, em nossa memória discursiva, os desastres ambientais, a degradação do ecossistema causada por utilização indevida de seus recursos e, com isso, emergem as formações discursivas científica e ambientalista articuladas ao discurso pedagógico do documento oficial.

Baseando-nos nas interpretações de R3, observamos que começa a ser reverberada a representação de território pelo discurso oficial: nos discursos vinculados à formação discursiva capitalista, a representação de terra também se encontra consorciada a essa ideologia. O objetivo de preservar os recursos existentes nesses territórios é, por sua vez, uma maneira politicamente correta de dizer “explorar os recursos oriundos desse espaço”, a fim de obter lucro, produção, comércio por um longo tempo.

Ressaltamos, contudo, que o Estado, apesar de demonstrar intradiscursivamente uma preocupação com a demarcação de terras e com o bem-estar das comunidades indígenas, deixa escapar uma procura em escamotear suas finalidades políticas a fim de revigorar sua face protetiva. Sabemos, pois, que a demarcação de terras no Brasil é um processo burocrático e lento, e que objetiva, na maioria das vezes, favorecer a elite, o que dificulta a aplicabilidade da lei de maneira igualitária, como propõe o aparato jurídico.

Nessa esteira, é afirmado pelo documento o direito das comunidades de terem suas terras e que esse direito encontra-se na base de todos os demais. Vejamos (grifo nosso):

\footnotetext{
R4: Estando o direito à terra na base do reconhecimento de todos os demais direitos indígenas e dadas as diversas situações de territorialidade que vivenciam, a questão do território ocupa um lugar central em seus projetos societários e movimentos políticos de reivindicação de direitos específicos, dentre eles a educação diferenciada
}

É dado a observar que o legislador, ao afirmar que os indígenas têm o direito à terra, e que este direito está na base do reconhecimento de todos os demais direitos 
indígenas, o discurso oficial busca silenciar o direito legítimo que estas comunidades têm sobre as suas terras, chamadas de terras tradicionais.

Com esse gesto, é deslegitimado o direito originário dos indígenas sobre suas terras e cria-se uma nova interpretação de que o Estado, generoso e protetivo, intervêm para garantir um direito, que, por sua vez, é de todos os cidadãos. O gesto de afirmar esse direito nos remete ao que Orlandi (2007, p. 73) denomina de silêncio constitutivo: ao nomear os índios como sujeitos de direitos e, sobretudo, de direito à terra, o enunciador apaga o fato de os europeus terem suprimido esse direito durante o colonialismo. Nesse sentido, ao fazer essa escolha discursiva, efeitos de sentido são circunscritos com o objetivo de apagar outros, e, assim, determinar os “limites do dizer” (ORLANDI, 2007, p. 74).

A partir do que discutimos, observamos que essas representações, veiculadas pelo documento oficial, são posicionadas com base no imaginário do branco, nesse viés, objetivando um paralelo entre as discursividades das Diretrizes e do povo Kinikinau, expomos os recortes que descortinam as representações de escola e território para o povo, que enfrenta a luta pelo reconhecimento étnico e a demarcação de suas terras tradicionais.

Envolvidos pela memória que, para Coracini (2007, p. 16), é “sempre esquecimento, pois é sempre interpretação de algo que passou; passado que se faz presente que, a todo momento, já é futuro”, o sujeito continua seu discurso a fim de relatar a luta do povo Kinikinau. SP1 afirma que (grifo nosso):

R5: SP1: e:: depois dessa luta... conseguimos esse reconhecimento... a nossa identidade né? conseguimos fazer a nossa identidade... até a cédula também de identidade pra... pra ser como Kinikinau...e::: 0 que nos falta agora: é só o território... então a escola pra gente foi... um grande caminho... é o primeiro passo para 0 nosso reconhecimento $[\ldots]^{5}$

O uso do termo “depois” desempenha a função de marcador temporal, em que o sujeito objetiva ordenar fatos inscritos na história de seu povo. O item lexical, portanto, vem demarcar, a fim de sequenciar a história dos Kinikinau, que é trazida à reflexão por meio da anáfora encapsuladora “dessa luta”, uma “retomada resumitiva”

\footnotetext{
${ }^{5}$ Entrevista concedida à pesquisadora em 15 de setembro de 2015 na aldeia São João.
} 
(CAVALCANTE, 2014, p. 80), além de dar continuidade a uma entidade já existente que se trata da busca pelo reconhecimento étnico e territorial.

Como se trata de um povo que, desde a era chaquenha já sofria constantes perseguições, sobretudo por questões de terra, os Kinikinau caracterizam-se por ser um povo que se adapta com facilidade. Essa adaptação não significa, entretanto, uma aceitação cabal das condições que lhes foram, e ainda o são, impostas. Ao contrário, esse povo, apesar de, após a guerra da Tríplice Aliança, num grupo já bastante reduzido, terse aglutinado aos Terena, vislumbrando sobreviver, em nenhum momento deixou de lutar por sua visibilidade, mesmo tendo sido considerado extinto na década de 1970, como afirma o sujeito em instantes anteriores ao recorte. Frisamos que a autoidentificação como Terena foi a maneira encontrada pelos Kinikinau para sobreviver em meio às guerras e perseguições, no entanto, com o passar do tempo, esse povo foi sendo esquecido pela sociedade hegemônica e, por conseguinte, considerado extinto por renomados pesquisadores, como Darcy Ribeiro e Roberto Cardoso de Oliveira.

Por meio da anáfora encapsuladora dessa luta, representa-se a situação relatada, e faz-se necessário, nesse viés, o deslocamento de sentido, ou seja, historicizar a palavra luta, que tem acepção dicionarizada de “combate corpo a corpo; conflito armado; batalha; guerra” (BECHARA, 2011, p. 968). O sentido veiculado pelo dicionário, apesar de bastante associado aos indígenas por meio da mídia, não representa, todavia, a luta à qual SP1 se refere.

A definição dicionarizada dessa palavra fazia, de fato, muito sentido para o índio de 500 anos atrás, mas não se aplica ao indígena de hoje, informado e tecnológico. Assim, o sentido da expressão, no discurso de SP1, está vinculado à luta contra a extinção de seu povo, que sofria um processo de (des)identificação, já que seus integrantes eram registrados como Terena pela Funai, mesmo estando ciente das diferenças étnicas existentes, e da violação de seus direitos, travando uma luta ideológica contra o Estado.

Posto isso, a luta descrita pelo índio não é a mesma luta descrita pelo branco, já que ambos discursivizam esses termos a partir de diferentes domínios discursivos. Episódios que frisam a diferença na representação de luta para os índios e para os brancos são as retomadas, a luta para reaver terras tradicionais, por exemplo. As retomadas de territórios tradicionais processam-se pela sequência “ocupação, plantio e construção de moradias”, caracterizada como luta e para que seus direitos sejam garantidos. Em 
contrapartida, a iniciativa de retomada é vista pelo branco como uma afronta, uma violação dos direitos constitucionais do outro, tendo em vista que a maioria das retomadas é realizada no seio de uma expectativa de aprovação judicial, como uma forma de pressionar a agilidade processual.

Tal entrave nos permite compreender ainda mais a relação desse povo com seu território tradicional, pois, nas palavras de Santos (2001, p. 3), “o movimento indígena é uma grande afirmação de que há relações sociais que são escritas em territórios e que só fazem sentido enquanto parte deles. As suas terras são sagradas, e são aquelas e não outras”. Essa representação não passa, porém, pelo imaginário do homem branco e, portanto, em suas redes de significação, não compreende tal relação.

Ao tolher a ação de retomada, acreditamos que o branco busca inviabilizar a ocupação, que, apesar de embasada em um direito constitucional, não possui respaldo legal eficiente, e impedir os índios, mesmo que com o uso da violência, de reaver suas terras tradicionais, que emanam história e memórias de seu povo. O branco, sujeito civilizado, hábil nas leis, representado de tal forma pela sociedade hegemônica como padrão de cidadão, ao usar a força, assume uma posição difundida, via mídia, de agressor, selvagem, “silvícola”, carregada do interdiscurso governamental, antes vinculada apenas ao índio.

Em decorrência disso, o índio, por meio dos conhecimentos que lhe foram impostos pela escola para civilizá-los e torná-los sujeitos fabricados por uma ideologia, direciona esses conhecimentos a seu favor, como uma forma de resistência. Hoje, o índio da descoberta, ou melhor, da “invasão” (ORLANDI, 2008, p. 42), atravessa o momento da tecnologia, do excesso de informação, a era da "sobremodernidade”, que se torna necessária para a sua sobrevivência, possibilitando sua visibilidade em espaços globais (AUGÉ, 2006, p. 103).

Durante sua fala, SP1 nos explicou que a relação com os donos da terra foi complicada pela construção de uma escola Kinikinau, e que esse fato tem gerado conflitos, tensão na aldeia, motivando diversas famílias a buscar abrigo em outras comunidades, na maioria das vezes, Terena. As tensões pelo fato de a escola ser Kinikinau enrijece a disputa entre os povos e indigna o sujeito, uma vez que este explica "se é uma... aldeia onde a maioria é Kinikinau por que tem uma escola Kadiwéu né?”6. O espaço

\footnotetext{
${ }^{6}$ Entrevista concedida à pesquisadora em 15 de setembro de 2015, na aldeia São João.
} 
escolar, nesse sentido, é disputado pelas duas etnias e funciona como um "barril de pólvora” na comunidade.

Refletindo acerca das questões históricas dos Kinikinau e das afirmações anteriores, via recortes, constroem-se, pela materialidade linguística, os efeitos de sentido de uma escola reformulada pela comunidade, uma escola do indígena e não para o indígena, apesar da face regulamentadora instituída pelo Estado à escola. Baseando-nos, assim, nos dizeres de SP1, em especial nas afirmações sobre a escola, pudemos observar que a comunidade Kinikinau tece uma relação diferente com a escola, se comparada a outras comunidades. Os gestos interpretativos nos direcionam para a representação de escola como um espaço de reafirmação étnica, sobretudo, no qual os Kinikinau, apesar de estarem em território alheio, têm um lugar próprio.

Escrever sobre território na perspectiva do indígena é um desafio, porém analisar seu discurso sobre o território é inenarrável, já que nos permite refletir sobre determinantes históricos e culturais que passam despercebidos quando, por exemplo, ouvimos em um noticiário o indígena requerer suas terras tradicionais e afirmar que o território de origem é tudo que seu povo precisa. Mas isso também nos faz refletir sobre as relações de poder e a presença do discurso do branco nos dizeres indígenas como forma de resistência.

Todas as práticas regidas pela globalização (trans)(de)formaram, no decorrer no tempo, a relação homem/natureza, além de terem se consolidado de maneira conflituosa, envolvendo sempre relações de poder, já que operam nos espaços da dicotomia inclusão/exclusão. A essas práticas elencamos o consumismo, o latifúndio, o desmatamento, entre outras, que condicionam os deslocamentos da representação de território, em especial para o índio.

Na atualidade, essas práticas são resultantes dos jogos de poder entretecidos por sujeitos que não estão nas bordas sociais envolvidos pelo discurso de progresso e evolução e, com isso, criam uma cisão em determinadas representações, uma vez que as representações que os sujeitos criam estão relacionadas a seus processos de identificação (CORACINI, 2007). Dessa forma, ressaltamos que as representações elaboradas pelo branco, em determinados aspectos, são ininteligíveis para os índios. Vejamos no excerto R6 a representação de território articulada por SP1 (grifo nosso): 
R6: SP1: a terra pra nóis... num tem que/não tem como explica né? ele é tudo... ele:: é como se fosse uma mãe... e a mãe... a gente não se vende/não vende... a mãe a gente cuida... então para o indígena é assim né? a terra a gente tem que cuida... e sobrevive da terra... porque:: como a mãe da gente... ah:: eh:: a mãe nos sustenta... então quem nos sustenta é a terra... tudo que vem da terra... são tudo o que é produzido da terra... são alimentação... agua... eh:: tudo que existe:: faz parte da vida... também dos indígena... pra mim a terra é isso... é a vida ${ }^{7}$

No início de seu dizer, é frisada a separação de sua identidade em relação à identidade do branco, estabelecendo distinções marcadas por oposição, sendo as identidades construídas por marcas de classificação (WOODWARD, 2013). A presença do referente nóis, funcionando como uma remissão endofórica e exofórica, já que não se refere apenas ao povo que reside na comunidade, mas a todo o povo que desde a saída do Chaco Paraguaio luta pela sobrevivência do grupo, restringe a representação de terra a ser descrita apenas aos Kinikinau. Ele mostra essa oposição usando a locução “para nóis”, os Kinikinau, indicando, com isso, a presença do outro silenciada no recorte, mas passível de recuperação por meio da referenciação. Outros itens lexicais como “a gente” e “nos” tonificam a distinção feita pelo sujeito entre o índio e o outro (o branco).

Uma das regularidades nesse recorte é o uso da palavra mãe, para descrever a representação de território para a comunidade. A acepção dicionarizada de mãe designa, conotativamente, “pessoa extremamente cuidadosa, zelosa” (BECHARA, 2011, p. 799), e é esse o sentido do emprego realizado pelo sujeito no momento em que metaforiza a representação do território: “é como se fosse uma mãe... e a mãe... a mãe a gente cuida...”. Outro aspecto pertinente no trecho em que SP1 faz essa relação território/terra-mãe é a relação interdiscursiva estabelecida por meio da expressão "e a mãe... a gente não se vende/não vende...”. Ao dizer que a terra não pode ser vendida, presentifica-se, via interdiscurso, o dizer do outro, do branco que vende, comercializa a terra como um produto. Diante dessa perspectiva, vender a terra é, para o indígena, vender a si próprio (a gente não se vende), como o deslizamento provocado pelo inconsciente nos mostra. Compreendemos, portanto, que a relação com o território é uma relação única, além, inclusive, da relação com a própria mãe: é uma relação de fidelidade, cuidado de si próprio, consorciada a uma formação discursiva cultural, divergente da formação

\footnotetext{
${ }^{7}$ Entrevista concedida à pesquisadora em 15 de setembro de 2015, na aldeia São João.
} 
discursiva capitalista que emana de itens lexicais como "vende”, recorrente no discurso do branco que atravessa o dizer indígena.

Baseando-nos, portanto, no imaginário indígena, a terra não pode ser vendida porque ela não é de ninguém, mas, ao mesmo tempo, é de todos e, em virtude da questão relacional, ressaltamos que a representação de território para o indígena é erigida sob circunstâncias diferentes, e isso acarreta a reflexão de que “A terra não é e não pode ser objeto de propriedade individual. De fato, a noção de propriedade privada da terra não existe nas sociedades indígenas” (RAMOS, 1986, p. 13-16).

Assim, no momento em que o sujeito discursa ("a mãe a gente cuida... então para o indígena é assim né? a terra a gente tem que cuida... e sobrevive da terra...”), ele expressa os laços afetivos para com o território em que vive e a maneira como os sujeitos Kinikinau lidam com o espaço em “a gente cuida”. Por meio dessa expressão, “a gente cuida”, emanam os sentidos de que os indígenas sim cuidam de suas terras, de seus espaços, já o branco não, pois ele o vende, o comercializa, se desfaz desse espaço como um produto, algo que não carrega sua história, não faz parte de si próprio.

Nestes trechos, “a mãe a gente cuida, a terra a gente tem que cuida”, há um diálogo com já-ditos, discursos outros como o de preservação, disseminado por uma formação discursiva ambiental. O sujeito manifesta a heterogeneidade em seus dizeres, por meio das não-coincidências do discurso, "a presença estrangeira de palavras marcadas como pertencendo a um outro discurso" (AUTHIER-REVUZ, 1998, p. 193) reafirmando um distanciamento entre si e o outro por meio de um jogo de palavras como vende, cuida, preservar, pra nóis.

Compreendemos que a repetição da palavra “mãe” no discurso do índio é um forte indício de demarcar, de ratificar as diferenças em que estão alicerçadas as representações de território para o índio e para o branco, além de corroborar a relação tradicional e cultural com o espaço, e, em especial, pelas formas de territorialização específicas da comunidade. Por se tratar de uma territorialização que transcende os fios de afetividade e entrelaça-se à identidade, no sentido de tornar-se Kinikinau por meio do território, os efeitos de sentido do referente “mãe” vão estar associados à cultura Kinikinau, expressão que melhor pode definir a relação da comunidade com o espaço em que vive, pois, segundo Hall (2013, p. 49), a cultura é uma produção, uma questão de “tornar-se”. 
A recorrente utilização da expressão “tudo”, como recurso catafórico, em “ele é tudo” lança um leque de significações que podem estar arroladas a ela, à medida que sua acepção dicionarizada refere “a totalidade, o essencial” (BECHARA, 2011, p. 1114). No decorrer de sua fala, o sujeito ressignifica esse “tudo" por meio da palavra "mãe”, que parece estar na mesma direção argumentativa simbólica, território - tudo - mãe - nos dá a vida. Tais reflexões são corroboradas pela afirmação do sujeito ao dizer que a terra, ou o território, concede tudo, assim como a mãe concede tudo o que é necessário ao filho, ela o sustenta, o alimenta, o protege, e da mesma ordem simbólica emerge o sentido de “tudo" utilizado por SP1, pois ele explica "são tudo o que é produzido da terra... são alimentação... agua... eh:: tudo que existe::.”.

A representação de território como mãe-provedora-protetora perpassa o discurso dos Kinikinau, mais que um território para construir suas casas é a representação de território como um lugar no qual as identidades se fortalecem, em que, conforme SP1, "é a vida”. Na sequência, o "tudo” é ressignificado a partir do momento que o sujeito diz “são tudo o que é produzido da terra... são alimentação... agua... eh:: tudo que existe:: faz parte da vida... também dos indígena... pra mim a terra é isso... é a vida”.

Como muitos povos indígenas, os Kinikinau têm uma relação social e cultural forte com a terra e tudo que está posto sobre ela, portanto, eles devem "sobrevive da terra...”. Para os indígenas, tudo o que a terra produz, assim como os animais, as árvores, sobretudo, o lugar no qual seus antepassados foram enterrados são sagrados e, por isso, devem ser respeitados e preservados.

\section{Algumas considerações}

Com base nas análises dos recortes, retirados do documento oficial, observamos que as representações que emergem apoiam-se em um imaginário colonizado, com o intuito de (trans)(de)formar as comunidades indígenas, por meio de uma escola que oferece uma educação escolar indígena para o índio baseada em princípios culturais antagônicos. Um exemplo que vai contra os valores e princípios indígenas e que, por sua vez, delineia bem esse posicionamento é a representação de território veiculada pelo documento, em que este é concebido como espaço para a produção econômica dos povos.

Em sentidos contrários estão as representações de escola e território construídas no discurso Kinikinau. $\mathrm{O}$ fato de estarem em condição diaspórica, mas se manterem ativos 
na busca pelo reconhecimento territorial, por meio da escola, demonstra a tomada de poder e o jogo de entrelaçamento que esse povo faz entre seus valores e os valores do branco, numa interpelação que os possibilita ganhar visibilidade e espaço na sociedade hegemônica. Pois, mesmo estando à margem, envolvidos por uma sociedade empenhada em calar a sua voz, os Kinikinau transformaram as imposições feitas pelo Estado em ferramentas de resistência, munindo-se, assim, de todas as possibilidades para se fortalecer e superar a exclusão.

Nesse sentido, apesar de estar associada à instituição governamental e consolidada a perspectiva de “identidade legitimadora” (CASTELLS, 2010), o nome da escola grafada em língua indígena Koinukunoen mobiliza uma interpretação distinta de escola. Os Kinikinau compreendem que o âmbito escolar, enquanto território em que a “democracia” se estabelece oportunizando momentos de (des)(re)construção identitária quando a língua Kinikinau é ensinada, quando valores e saberes desse povo junto aos conhecimentos universais são transmitidos aos alunos, é o que os fortalecerá, que ampliará a visibilidade diante da sociedade hegemônica na busca por seu território. Esse mecanismo de resistência veiculado pelo “saber-poder” (FOUCAULT, 2012) é que molda os sujeitos de uma sociedade.

Por fim, constatamos que as representações que emergem dos recortes demonstram o papel singular que a escola tem desempenhado na comunidade e como a instituição foi modelada às demandas desse povo. Além disso, a representação de território expressa pelo sujeito indígena demonstra como a relação entre a terra e a comunidade é agenciada por determinantes históricos e culturais particulares, capazes, apenas, de passar pelo fio das significações daqueles que compartilham o sentimento de ser índio brasileiro e de pertencer a essas terras.

SANTOS, Daniele Lucena; SOUZA, Claudete Cameschi. Between the official discourse and the Kinikinau discourse: school and territory representations. Revista do Gel, v. 14, n. 1, p. 77-103, 2017.

Abstract: Based on the discourse of the official document of the National Curriculum Guidelines for Indigenous Education in Basic Education (2012) and on the discourse of Kinikinau people, we aim to discuss the identity construction of Kinikinau and analyze the school and territory representations that pervade these discourses. In order to seek, 
by relying on the enunciative regularities, the discursive formations and interdiscourse that weave the discursive threads, targeting a discussion on the effects of generated senses, we developed this article under the cross-disciplinary perspective of French Discourse Analysis, dialoguing with cultural studies and based on the language referencing process and on Foucault archeogenealogic method (2008. 2012). Based on the studies of Authier-Revuz (1998); Coracini (2007); Foucault (2008, 2012); Orlandi (2008, 2009); Pêcheux (1988); Bauman (2005); Castells (2010) and Hall (2012), we found that the Kinikinau, standing on the border territory, redefine their social practices, and that the discourse of the official document points to school and territory representations crossed by discursive formations and interdiscourses linked to political matters, contrary to the objectives for which it was created and diverging from representations built by Kinikinau articulated in cultural principles.

Keywords: Kinikinau. School. Territory. Identity.

Submetido em: 03/05/2016.

Aceito em: 21/12/2016.

\section{Referências}

ACHARD, P. Papel da Memória. Tradução de José Horta Nunes. Campinas: Pontes, 1999.

AUGÉ, M. Sobremodernidade: do mundo tecnológico de hoje ao desafio essencial do amanhã. In: MORAES, D. Sociedade midiatizada. Rio de Janeiro: Mauad, 2006. p. 99117.

AUTHIER-REVUZ. J. Palavras incertas: as não-coincidências do dizer. Campinas: Editora da UNICAMP, 1998.

BARONAS, R. L. Ensaios em Análise de Discurso: questões analítico-teóricas. São Carlos: EdUFSCar, 2011.

BAUMAM, Z. Identidade: entrevista a Benedetto Vecchi. Rio de Janeiro: Zahar, 2005.

BECHARA, E. Dicionário da Língua Portuguesa. Rio de Janeiro: Editora Nova Fronteira, 2011.

BRASIL, Ministério da Educação. Conselho Nacional de Educação. Diretrizes Curriculares Nacionais para a Educação Escolar Indígena na Educação Básica. Brasília, 2012. Diário Oficial da União: 15 de junho de 2912, Seção 1, p. 18. Disponível em:

$<$ http://portal.mec.gov.br/index.php?option=com_docman\&view=download\&alias=108 06-pceb013-12-pdf\&category_slug=maio-2012-pdf\&Itemid=30192>. Acesso em: 05 jul. 2014. 
BRASIL, Ministério da Educação. Secretaria de Educação Continuada, Alfabetização, Diversidade e Inclusão (SECADI/MEC) MINISTÉRIO DA EDUCAÇÃO (2007). Educação Escolar Indígena: diversidade sociocultural indígena ressignificando a escola. Brasília, Cadernos SECAD 3, 2007.

CASTELLS, M. O poder da identidade. Tradução de Klauss Brandini Gerhardt. 6. ed. São Paulo: Paz e Terra, 2010.

CAVAlCANTE, M. M. et al. Coerência, referenciação e ensino. São Paulo: Cortez, 2014.

CORACINI, M. J. Um fazer persuasivo: o discurso subjetivo da ciência. São Paulo: EDUC; Campinas: Pontes, 1991.

A celebração do outro: arquivo, memória e identidade: línguas (materna e estrangeira), plurilinguismo e tradução. Campinas: Mercado de Letras, 2007.

FISCHER, R. M. B. Foucault. In: OLIVEIRA, L. A. (Org.). Estudos do Discurso: perspectivas teóricas. São Paulo: Parábola Editorial, 2013. p. 123-151.

FOUCAULT, M. Arqueologia do saber. Tradução de Luiz Felipe Baeta Neves. 7. ed. Rio de Janeiro: Forense Universitária, 2008.

A ordem do discurso. Tradução de Laura Fraga de Almeida Sampaio. 19. ed. São Paulo: Loyola, 2012.

GÓIS, M. L. de S. Discursos sobre a demarcação de terras indígenas... ou de como a raposa encontrou a Serra do Sol. Dourados: Editora da UFGD, 2013.

GUERRA, V. M. L. O Indígena de Mato Grosso do Sul: práticas identitárias e culturais. São Carlos: Pedro \& João Editores, 2010.

HALL, S. Quem precisa da Identidade? In: SILVA, T. T. da. Identidade e diferença: a perspectiva dos estudos culturais. 12. ed. Petrópolis: Vozes, 2012. p. 94-126.

ORLANDI, E. P. As formas do silêncio. 6. ed. Campinas: Editora da Unicamp, 2007.

Terra à vista. Discurso do confronto: Velho e Novo mundo. 2. ed. Campinas: Editora da UNICAMP, 2008. 2009.

Análise de Discurso: princípios \& procedimentos. 8. ed. Campinas: Pontes,

PÊCHEUX, M. Semântica e Discurso. Uma Crítica à Afirmação do Óbvio. Tradução de Eni P. de Orlandi et al. Campinas: Editora da UNICAMP, 1988 [1975]. 
SANTOS, B. de S. A territorialização/desterritorialização da exclusão/inclusão social no processo de construção de uma cultura emancipatória. In: Seminário: "Estudos Territoriais de desigualdades sociais”. v. 1, 2001. São Paulo, Anais do Seminário: “Estudos Territoriais de desigualdades sociais”, São Paulo: PUC, 2001, p. 06-17. Disponível em: <http://www.dpi.inpe.br/geopro/exclusao/Boaventura.pdf>. Acesso em: 02 jan. 2016.

Renovar a teoria crítica e reinventar a emancipação social. Tradução de Mouzar Benedito. São Paulo: Boitempo, 2007.

SANTOS, D. L.; SOUZA, C. C. de. Pelos percursos históricos e linguísticos, o povo Kinikinau. Anais do IV Seminário América Platina, 2014. p. 138-153. Disponível em: $<$ http://www.seminarioamericaplatina.com>. Acesso em: 10 fev. 2015.

SOUZA, I. de. KOENUKUNOE EMO 'U: A língua dos índios Kinikinau. 2008. 196 f. Tese (Doutorado em Linguística) - Instituto de Estudos da Linguagem, Universidade Estadual de Campinas, Campinas, 2008.

SOUSA, K. M. de. Análise de Discurso: para além das vertentes sociológica e formalista da linguística. In: BARONAS, R. L.; MIOTELLO, V. Análise de discurso: teorizações e métodos. São Carlos: Pedro \& João Editores, 2011. p. 103-114.

SOUZA, R. de A. Sustentabilidade e processos de reconstrução identitária entre o povo indígena Kinikinau (Koinukunoen) em Mato Grosso do Sul. 2012. 58 f. Dissertação (Mestrado em Desenvolvimento Sustentável) - Centro de Desenvolvimento Sustentável, Universidade de Brasília, Brasília, 2012.

RAMOS, A. Sociedades indígenas. São Paulo: Ática, 1986.

WOODWARD, K. Identidade e diferença: uma introdução teórica e conceitual. In: SILVA, T. T. da. (Org.). Identidade e diferença: a perspectiva dos estudos culturais. Petrópolis: Vozes, 2013. p. 55-93.

ZOPPI-FONTANA, M. G. Arquivo jurídico e exterioridade. A construção do corpus discursivo e sua interpretação/interpretação. In: GUIMARÃES, E.; PAULA, M. R. B. de. (Org.). Sentido e Memória. Campinas: Pontes, 2005. p. 93-113. 